\title{
Formulation and Stability Testing of Nanoemulsion Lotion Containing Centella asiatica Extract
}

\author{
Muthia Hanifah*, Mahdi Jufri \\ Faculty of Pharmacy, Universitas Indonesia, Depok, INDONESIA.
}

\begin{abstract}
Objective: Centella asiatica (Pegagan) contains asiaticoside for treatment of striae patients by increasing the synthesis of collagen. Asiaticoside has a large hydrophilic molecule $(959.12 \mathrm{~g} / \mathrm{mol})$, causing difficulty in penetration through the skin. Nanoemulsion has small droplet size so that the active substance can be delivered into the skin layer. This study aims to formulate and test the stability of nanoemulsion lotion containing pegagan extract. Methods: Nanoemulsion containing pegagan extract formulated in the form of lotion using High Pressure Homogenizer. Nanoemulsion lotion were then evaluated and tested for penetration in vitro. Result: The mean particle size of nanoemulsion was $19.88 \pm 2.3 \mathrm{~nm}$ and nanoemulsion in lotion was $198.4 \pm 11.52 \mathrm{~nm}$; polydispersity index value $0.329 \pm 0.065$, and zeta potensial was $-30.9 \mathrm{mV}$. Nanoemulsion lotion was stable against storage for 8 weeks at cold, room, and high temperature $\left(4 \pm 2{ }^{\circ} \mathrm{C}, 28 \pm 2{ }^{\circ} \mathrm{C}\right.$, $40 \pm 2^{\circ} \mathrm{C}$ ). There were no change in physical properties and $\mathrm{pH}$ value of the nanoemultion lotion. The cumulative amount of the penetrated asiaticoside was
\end{abstract}

$1558.65 \pm 66.93 \mu \mathrm{g} / \mathrm{cm}^{2}$ for nanoemulsion lotion and $1260.364 \pm 71.42 \mu \mathrm{g} / \mathrm{cm}^{2}$ for lotion only. Flux of nanoemulsion lotions and lotion were $2.1255 \pm 0.31$ $\mu \mathrm{g} / \mathrm{cm}^{2} / \mathrm{hr}$ and $1.4506 \pm 0.49 \mu \mathrm{g} / \mathrm{cm}^{2} / \mathrm{hr}$, respectively. Conclusion: It can be concluded that nanoemulsion lotion stable in physical properties during storage and can penetrate more than the non nanoemulsion lotion.

Key words: In vitro penetration lotion, Nanoemulsion, Pegagan extract, Stability test.

Correspondence

Ms. Muthia Hanifah, Faculty of Pharmacy, Universitas Indonesia, INDONESIA. Phone: +6281280062849

Email: muthia912@gmail.com

DOI: $10.5530 /$ jyp.2018.10.89

\section{INTRODUCTION}

Striae distensae or stretch marks are common skin lesions that arise because of the stretching of the dermis which is mostly suffered by pregnant women and teenagers. Striae can be treat by increasing the production of collagen and elastin fibers in the skin as well as other therapies. Topical therapy aims to provide improved pigmentation and texture of the striae with minimal side effects for patients of all skin types. There is a product on the market in the form of cream (Limforma ${ }^{\oplus}$ ) which contains active compound of pegagan and declared to prevent striae. A product comparative study states that the effect of using Limforma ${ }^{\oplus}$ is more satisfactory subjectively. ${ }^{1}$

Centella asiatica (Pegagan) can be used for photoaging, cellulite and striae. The content of pegagan to heal striae is asiaticoside. Asiaticoside able to induce the synthesis of collagen type I in fibroblasts with both phosphorylation of Smad 2 and Smad 3, also binds Smad 3 and Smad $4 .^{2}$ In other studies, cream that contain pegagan extract able to prevent striae in women with a history of striae during puberty in $89 \%$ of cases, whereas all women in the placebo group had striae. ${ }^{3}$

Asiaticocide has a molecular weight of $959.12 \mathrm{~g} / \mathrm{mol}$, a water solubility of $307,347 \mathrm{pg} / \mathrm{mL}$, and a partition coefficient of $2.24 .^{4}$ The poor solubility of asiaticocide in water or oil and large molecular weight results in weak yielding effects, inhibits the absorption process, and difficult in formulating. ${ }^{5}$ Therefore, to increase the absorption, pegagan is formulated into nanoemulsion to enhance its effectiveness.

Nanoparticle technology in the form of nanoemulsion, is an effective method in the delivery of active substances. Nanoemulsion have a small droplet size, less than $300 \mathrm{~nm}$, making it easier to penetrate past the layers of the skin and increase the content of pegagan extracts that penetrate the skin. The nanoemulsion-forming components are the active substances, oils, surfactants / cosurfactants, aqueous solutions, and other additive components. Nanoemulsion also be made to prevent the occurrence of creaming, flocculation, coalescence, and sedimentation, as well as more stable than regular emulsions. ${ }^{6}$

Lotion is emulsion in an aqueous vehicle. An emulsion is considered to be physically unstable if the internal phase upon standing tends to form aggregates of globules, aggregates of globules rise to the top or fall to the bottom of the emulsion to form a concentrated layer of the internal phase, and can forms a distinct layer on the top or bottom of the emulsion as a result of the coalescing of the globules of the internal phase. ${ }^{7}$ Therefore, stability test is required to ensure that the preparation is stable and wont creaming or breaking.

Furthermore, lotion preparation increases the risk that the globules will coalesce. According to Stokes' equation, the rate of separation of the dispersed phase of an emulsion may be related to such factors as the particle size of the dispersed phase. Therefore, to increase the stability of an emulsion, the globule or particle size should be reduced as fine as is practically possible. The reduced particle size of the oil globules may render the oil more digestible and more readily absorbed. ${ }^{8}$

Based on these things, the issues to be examined in this study are the formulation nanoemulsion containing extracts of pegagan, formulation of lotion containing nanoemulsion extracts of pegagan, evaluation and stability testing of nanoemulsion lotion contains extracts of pegagan, and the penetration profiles of asiaticoside in nanoemulsion lotion form in to skin layer. This study aims to formulate, test the physical stability, and get the profile of penetrated nanoemulsion lotion containing the extract of pegagan. 


\section{MATERIALS AND METHODS}

\section{Materials}

Ethanolic extract of Centella asiatica (Balittro, Indonesia), asiaticoside standard 94.25\% (Guangxi Changzhou Natural Pharmacetical, China), olive oil (Brataco Chemical, Indonesia), isopropyl myristate (Palm-Oleo (Klang) (Brataco Chemical, Indonesia), stearic acid, TEA, cetyl alcohol, glycerin, BHT, methyl paraben, propyl paraben, phosphate buffer, chloroform (Merck, Germany), methanol (Merck, Germany), aquademineralisata (Brataco Chemical, Indonesia), and skin of Sprague Dawley rat weighing $\pm 200 \mathrm{~g}$ (Bogor Agricultural Institute, Indonesia, Ethical Number: 17-02-0179).

\section{Extraction and determination of asiaticoside}

The leaves of pegagan, was extracted by maceration for $24 \mathrm{~h}$ using $70 \%$ ethanol as solvent. Determination of asiaticoside content in the extract of pegagan was done using thin layer chromatography (TLC) densitometry. The eluent was a mixture of chloroform-methanol-water $(58: 38: 4)(\mathrm{v} / \mathrm{v})$. $2 \mu \mathrm{L}$ of samples solution of asiaticoside were bottled on the TLC plate. Spots were detected with Lieberman-burchard solution. Then an analysis was done using TLC densitometry at wavelength $575 \mathrm{~nm}{ }^{9}$

\section{Construction of Pseudo-Ternary Phase Diagram}

The phase diagram of nanoemulsion was formed from water titration on the oil phase mixture with a surfactant-cosurfactant mixture. Surfactant, Tween 80 , and cosurfactant, 96\% ethanol and propylene glycol, were mixed at a ratio of Tween 80 -ethanol 96\% -propylene glycol (6:3:1). The oil phase, isopropyl myristate, was mixed into a mixture of surfactantcosurfactant with a ratio of 9:1, 8:2, 7:3, 6:4, 5:5, 4:6, 3:7, 2:8, and 1:9 $(\mathrm{w} / \mathrm{w}){ }^{10}$ The mixture is observed visually to form a cloudy saturated liquid that indicates the formation of nanoemulsion. The volume of water, oil, and surfactant-cosurfactant based on the results of the experiment was entered the CHEMIX School 3.60 program. The program will display the point that connects the region of nanoemulsion formation.

\section{Nanoemulsion Lotion of Pegagan}

Nanoemulsion made with Tween 80 was poured into aquademineralisata and homogenized it by homogenizer at $1000 \mathrm{rpm}$. Isopropyl myristate was added into the homogenized mixture gradually and the speed of homogenizer raised to $2000 \mathrm{rpm}$. Extract of pegagan was dissolved in mixture of $96 \%$ ethanol and propylene glycol in another container. The mixture of pegagan extract is added into the isopropyl myristat-Tween 80 mixture which is homogenized at $2000 \mathrm{rpm}$ for $3 \mathrm{~min}$. Completed nanoemulsion was kept for $24 \mathrm{~h}$ to see if nanoemulsion formed.

The oil phase that are stearic acid, cetyl alcohol, olive oil, and aqueous phases that are aquademineralisata, TEA, propylene glycol, methyl paraben, and propyl paraben, were mixed together at $70^{\circ} \mathrm{C}$ and homogenized to form the base of the lotion. Citric acid is firstly dissolved in water (1:10) and added to the base of the still-homogenized homogenizer lotion. The lotion is then homogenized with a high-pressure homogenizer (HPH) with a pressure of 400 barr for 7 cycles.

\section{Evaluation Nanoemulsion Lotion of Pegagan preparations}

\section{Physical appearance}

Nanoemulsion lotion formulas were inspected for their colour, odor and homogeneity and phase separation nanoemulsion lotion.

\section{2. $\mathrm{pH}$ measurement}

The $\mathrm{pH}$ value of the nanoemulsion lotion of pegagan was measured using $\mathrm{pH}$ meters. The nanoemulsion lotion preparation was measured by dissolving $1 \mathrm{~g}$ of nanoemulsion lotion sample with $10 \mathrm{~mL}$ of aquadest. $\mathrm{pH}$ meters of which the electrode was calibrated with standard buffer $\mathrm{pH} 4$ and 7 was inserted into the dissolved preparation, and a $\mathrm{pH}$ value appeared on the screen.

\section{Particle size measurement}

Particle size measurement was carried out with dynamic light scattering with zetasizer (Malvern instruments ltd., Malvern, U.K). The polydispersity index and zeta potential of the formulation was determined by the same instrument

\section{Transmission Electron Microscopy}

TEM was used to visualize globules of nanoemulsion of pegagan using TEM JEOL JEM 1400. Nanoemulsion was dried on a carbon coated copper grid. After drying, the morphology of samples globules was observed under microscope $100 \mathrm{kV}-200 \mathrm{kV}$. $^{11}$

\section{Rheology Properties}

The rheology and viscosity of the nanoemulsion lotion formula was determined using Brookfield viscometer attached with spindle number 3 . The-spindle was set to rotate from $0.5,2.0,5.0,10.0$ and 20.0 and changed to $20.0,10.0,5.0,2.0,0.5 \mathrm{rpm}$. It was used for dialling the reading at each rpm. The rheological behavior of each system was evaluated by plotting the shear stress versus the shear rate values. The viscosity values were recorded.

\section{Physical Stability Study Nanoemulsion Lotion of Pegagan}

To observe any change in nanoemulsion lotion stability, it was stored at $4^{\circ} \mathrm{C} \pm 2^{\circ} \mathrm{C}$ for $24 \mathrm{~h}$ and followed by $24 \mathrm{~h}$ at $40^{\circ} \mathrm{C} \pm 2^{\circ} \mathrm{C}$ (Cycling test). The cycle was repeated six times. Nanoemulsion lotion was loaded into centrifugation tube and was centrifuged at $3750 \mathrm{rpm}$ for $5 \mathrm{~h}$, then it was observed for any change in homogeneity. Becher in Lachman and Lieberman indicates that centrifugation at $3750 \mathrm{rpm}$ for $5 \mathrm{~h}$ is equivalent to gravity effect for approximately one year. ${ }^{12}$

Samples of nanoemulsion lotion of pegagan were stored in different temperature condition, which are room condition $28^{\circ} \pm 2^{\circ} \mathrm{C}$; high temperature $40^{\circ} \pm 2^{\circ} \mathrm{C}$; low temperature $4^{\circ} \pm 2^{\circ} \mathrm{C}$ for 8 weeks. This was done to evaluate its physical stability through visual inspection in physical change such as color and phase separation every 2 weeks.

\section{In vitro skin penetration}

The penetration test of the nanoemulsion lotion was performed on mice abdominal skin that hairs were removed using Franz diffusion cells. In the receptor compartment was filled with $15 \mathrm{~mL}$ if phosphate buffer $\mathrm{pH}$ 7.4: $70 \%$ ethanol (1:1), maintained at $37 \pm 0.5^{\circ} \mathrm{C}$, and stirred with a magnetic stirrer at $300 \mathrm{rpm}$. $70 \%$ Ethanol was used to equalize test condition with determination of aciaticoside in pegagan extract. The sample applied sufficiently to the skin surface in the donor compartment. A total of $3 \mathrm{~mL}$ samples was taken periodically for 8 hat $\min 10,20,30$, $45,60,90,120,180,240,360$, and 480 from receptor compartments using syringes and replaced with equal amounts of phosphate buffer $\mathrm{pH}$ 7.4-70\% ethanol. The concentration of sample then measured by TLC densitometry.

\section{RESULTS}

\section{Extraction and determination of asiaticoside}

Pegagan extract was thick green-dark liquid. The linear regression equation from making standard calibration curve of asiaticoside with $70 \%$ ethanol solvent was $y=-155.25+6.58 x$ with correlation coefficient value $(r)$ of 0.9977 and asiaticoside content in extract of pegagan obtained was 46.82 $\pm 0.59 \%$. 


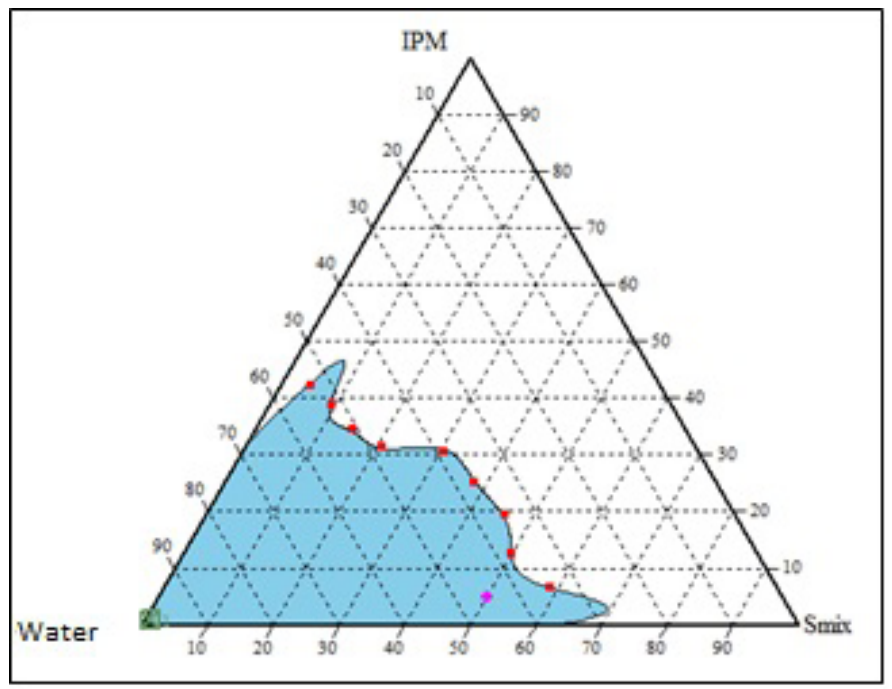

Figure 1: Pseudoternary phase diagram of nanoemulsion.

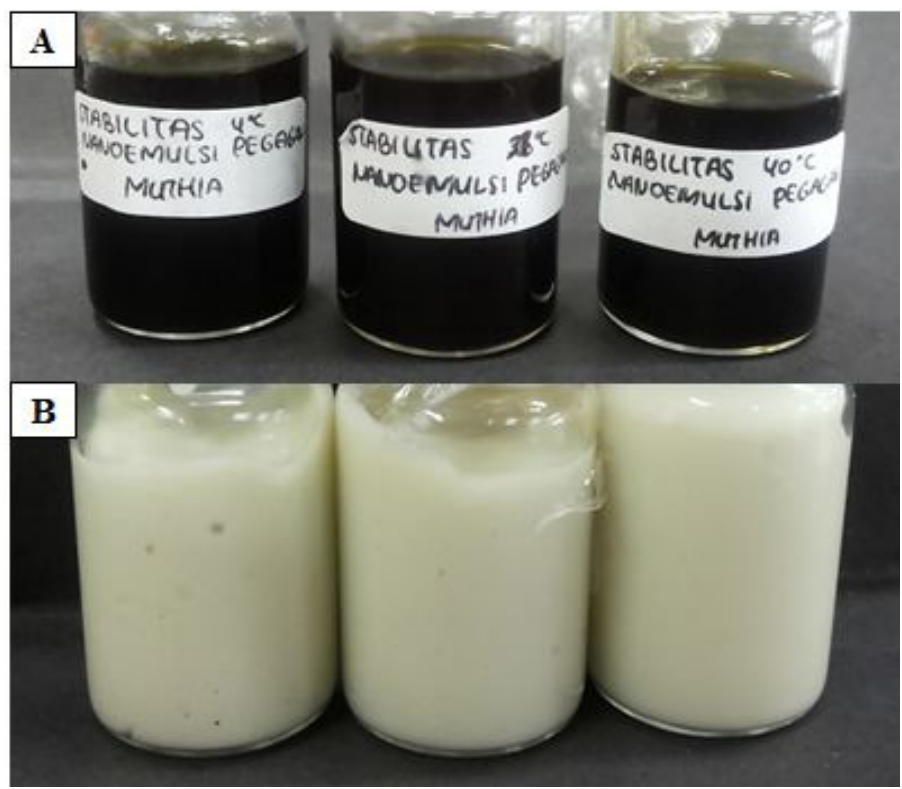

Figure 2: Physical appearance of (A) nanoemulsion and (B) nanoemulsion lotion.

\section{Construction of Pseudo-Ternary Phase Diagram}

The colored area in Figure 1 refers to nanoemulsion region. Nanoemulsion consist of small oil droplets dispersed in water (o/w nanoemulsion). The greater the concentration of isopropyl myristate added, the smaller the mixture of surfactant and co-surfactant. The formula used is a formula marked by a pink dot located in the nanoemulsion area.

\section{Nanoemulsion Lotion of Pegagan}

The optimized nanoemulsion contain 5\% isopropyl myristate, $30 \%$ tween $80,15 \%$ ethanol, and $5 \%$ propylene glycol. Lotion base was prepared by saponification methods using stearic acid and triethanolamine.

\section{Evaluation Nanoemulsion Lotion of Pegagan preparations}

1. Physical appearance

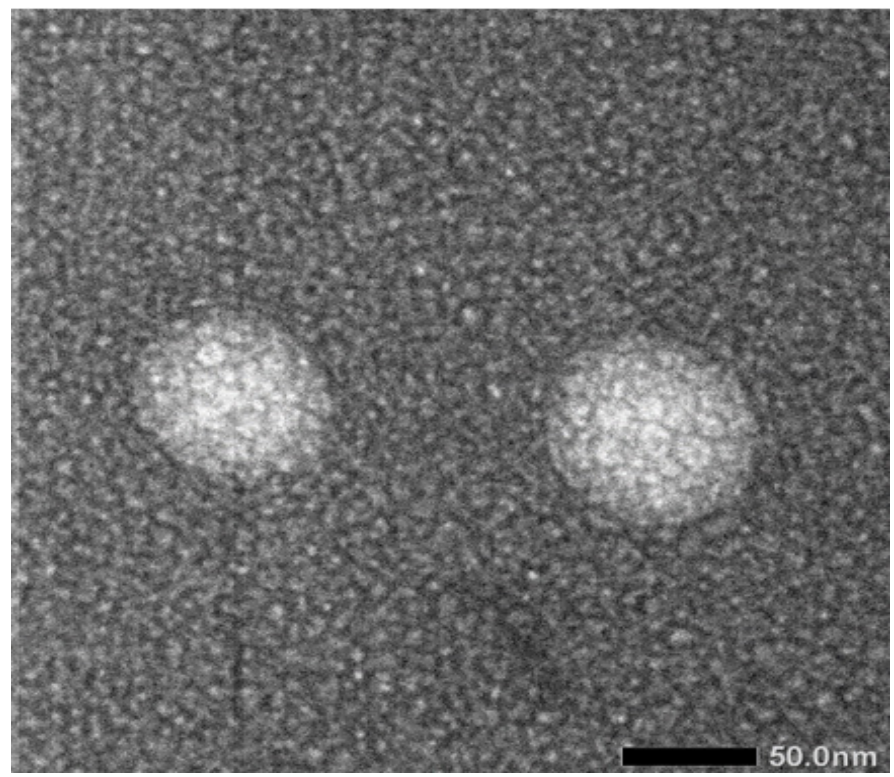

Figure 3: Particles of nanoemulsion lotion by Transmission Electron Microscopy.

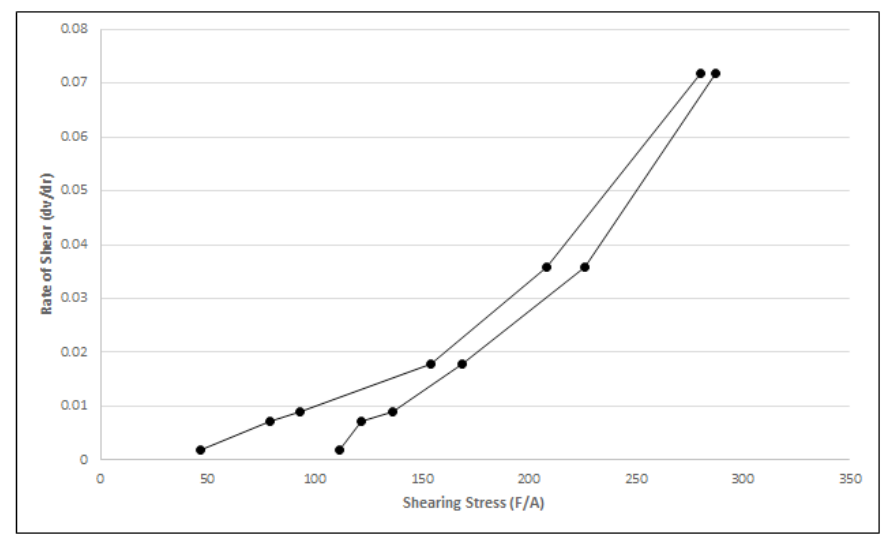

Figure 4: Rheogram of Nanoemulsion Lotion.

Nanoemulsion was green-dark liquid and smells like an extract or herb. Nanoemulsion lotion showed a light green color, smells like an extract or herb, there were pores on the surface has a non-sticky and non-greasy semi-solid texture when applied to the skin.

Nanoemulsion lotion has spherical shape (Figure 3).

\section{Rheology Properties}

Nanoemulsion lotion has a thixotropic plastic flow property (Figure 4). Based on the measurement results at a speed of $0.5 \mathrm{rpm}$, the viscosity value of nanoemulsion lotion was $62,000 \mathrm{cps}$.

1. pH measurement

Nanoemulsion lotion has a $\mathrm{pH}$ of 6.39

2. Transmission Electron Microscopy

Table 1: pH value of nanoemusion lotion.

\begin{tabular}{lll}
\hline & pH & Mean \pm SD \\
\hline Losio nanoemulsi & 6,40 & \\
& 6,40 & $6,39 \pm 0,005$ \\
& 6,39 & \\
\hline
\end{tabular}


Hanifah and Jufri.:Formulation and Stability Testing of Nanoemulsion Lotion Containing Centella asiatica Extract

Table 2: Size measurement, polydispersity index and zeta potential result.

\begin{tabular}{cccc}
\hline & Globul size $(\mathrm{nm})$ & Polydispersity index (PDI) & Zeta Potensial (mV) \\
\hline Nanoemusion & $19.88 \pm 2.3$ & 0.263 & $-3.37 \pm 0.13$ \\
Nanoemulsion lotion before homogenized with HPH & $4380 \pm 518.29$ & 0.690 & - \\
Nanoemulsion lotion after homogenized with HPH & $198.4 \pm 11.52$ & 0.329 & $-30.9 \pm 0.15$ \\
\hline
\end{tabular}

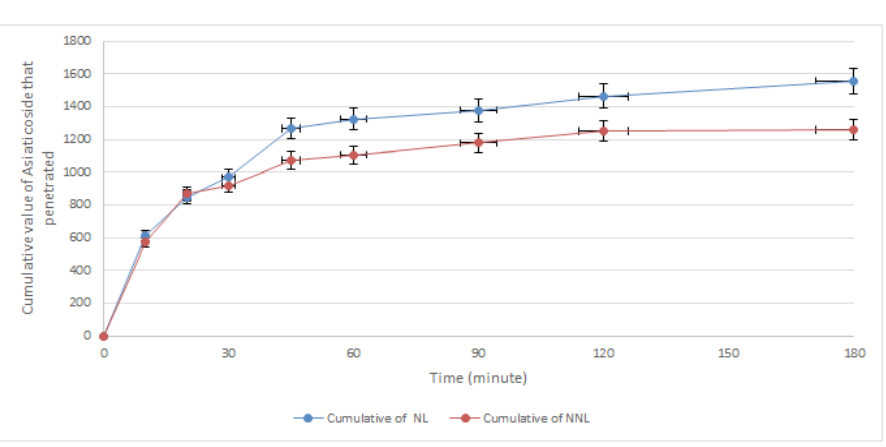

Figure 5: Cumulative value of asiatocoside in Nanoemulsion Lotion (NL) and Non-Nanoemulsion Lotion (NNL) that penetrated skin.

\section{Particle size measurement}

\section{Physical Stability Study Nanoemulsion Lotion of Pegagan}

Physical stability test of nanoemulsion lotion was done like cycling test, centrifugation, and 3 temperature storages. The observation of physical change of nanoemulsion lotion showed that there was no phase separation, discoloration, and change of odor.

\section{In vitro skin penetration}

Nanoemulsion lotion has an asiaticoside content of $0.2337 \pm 0.02 \%$, the cumulative value that penetrated skin was $1558.645 \pm 66.93 \mu \mathrm{g} / \mathrm{cm}^{2}$, and flux of $613.77 \pm 135.08 \mu \mathrm{g} / \mathrm{cm}^{2}$. The absorption of asiaticoside has occurred since the first sampling at minute 10 determined by TLC densitometry. In Figure 5 the concentration of the initial asiaticoside absorbed at min 10 on the nanoemulsion lotion (NL) was more than the concentration of non-nanoemulsion lotion (NNL). However, the amount of asiaticocide penetrated between the two preparations did not differ greatly. The direct curve rises because sampling at each time is too much so that the receptor medium becomes rapidly saturated.

\section{DISCUSSION}

Pegagan was extracted with $70 \%$ ethanol to obtain a water-less soluble asiaticocide content. Pegagan extract was mixed with $96 \%$ ethanol and propylene glycol to enhance dissolving of pegagan extract.

The surfactant used was nonionic groups, Tween 80 that has HLB 15 . Nonionic groups were selected because they were relatively non-toxic and non-irritating compared to anionic or cationic surfactant. The cosurfactants used were mixed of $96 \%$ ethanol and propylene glycol, both are short chain alcohols. Cosurfactant has a small molecule that can quickly be on the surface of water and oil and helped two phases to mix. The use of surfactants-cosurfactants in the manufacture of nanoemulsion were to reduce the interface tension of the water and oil phase layers. ${ }^{13}$

From Figure 1 it is known that the more oil phase was added the less the required surfactant-cosurfactant mixture was required. To form the nanoemulsion, from the oil phase, surfactant-cosurfactant, and the water, a greater number of water phases was needed than the oil phase and surfactant-cosurfactant mixtures were required. Globule of nanoemulsion lotion formed a spherical shape and there is a boundary between oil particle (inner) and water particle (Figure 3). Thus, that surfactant was appropriated to make nanoemulsion stable.

The lotion in nano-sized particle cannot achieved during process with homogenizer. Since the concentration of nanoemulsion that inserted was too small, so the particle size distribution was dominated by the lotion particles. The particle size was not included in the nanoemulsion range so that needed reduction of particle size by High Pressure Homogenizer. High pressure homogenizer forces the lotion through a narrow slit to quickly with great pressure. This causes high shear stress, turbulence and cavitation. The turbulence causes the particles to shrink. ${ }^{14}$

The results of $\mathrm{pH}$ measurement showed that $\mathrm{pH}$ values of nanoemulsion lotion was acceptable for normal human skin which $\mathrm{pH}$ between 5,5 - 6,4, so skin irritation can be avoided. ${ }^{15}$

Nanoemulsion lotion has smaller potential zeta than nanoemulsion. The smaller potential zeta value represents electrostatic repulsion between particles in nanoemulsion was larger so that the particles are not easily aggregated. ${ }^{16} \mathrm{PDI}$ is a measurement of particle homogeneity and it varies from 0.0 to 1.0. If PDI value closer to 0.0 it indicates narrow size distribution of the formulation. This showed that nanoemulsion has a more homogenous particle size distribution than nanoemulsion lotion before homogenized with HPH. After homogenized with HPH the particle size distribution becomes more homogeneous seen from its PDI value. ${ }^{17}$

Plastic flow is indicated by curves that do not cut $y$-axis and called a yield value. Nanoemulsion lotion will not flow until the presence of a shear stress exceeds the yield value. Yield value happens because the contact of adjacent particles due to the van der Waals bonds that must be discontinued to make lotion flow. The adjacent particles show flocculation, the more flocculation occurs, the higher the yield value. The thixotropic flow is indicated by a downward curve located to the left of the ascending curve. The decreasing curve shows the consistency of lotion to be low to the shear rate. This is due to the breaking of bonds on the particles that do not immediately bind back when the tension is reduced or eliminated. Consistency of the lotion will return due to bond between particles due to random Brownian motion. This indicates that the viscosity of lotion will decrease as there are particles that not re-forming to the initial bond after breaking of the bonds occurs along with the shear rate. ${ }^{18}$

The nanoemulsion lotion substance provided a higher asiaticoside flux than the non-nanoemulsion lotion product. The rate of penetration was faster in the nanoemulsion lotion than in the non-nanoemulsion lotion formulation. The higher permeation of nanoemulsion may be the result of a combination of the effects of small molecule of nanoemultion, ethanol, and surfactant. Other factors that may affect drug absorption through the skin are the viscosity of the preparation, the dissolution of a drug in the carrier, the diffusion of a dissolved drug from the carrier to the surface of the skin, and the penetration of drugs through the skin, especially the stratum corneum layer. ${ }^{19}$

\section{CONCLUSION}

Based on the result of the research, it can be concluded that the formulation of the nanoemulsion lotion has stable during two months of storage. The nanoemulsion lotion showed a higher flux compared to nanoemulsion 
base. For better results, it is advisable to apply pressure and cycle optimization during process of lotion using High-Pressure Homogenizer ( $\mathrm{HPH})$.

\section{CONFLICT OF INTEREST}

The authors declare no conflict of interest.

\section{REFERENCES}

1. Ud-Din S, McGeorge D, Bayat A. Topical management of striae distensae (stretch marks): Prevention and therapy of striae rubrae and albae. J Eur Acad Dermatol Venereol. 2015;30(2):211-22.

2. Bylka W, Znajdek-Awizen P, Studzinska-Sroka E, Brzezinska M. Centella asiatica in cosmetology. Advances in Dermatology and Allergology. 2013:( 1):46-9.

3. Mallol J, Belda M, Costa D, Noval A, Sola M. Prophylaxis of Striae gravidarum with a topical formulation, A double blind trial. Int J Cosmet Sci. 1991;13(1):51-7.

4. James J, Dubery I. Identification and quantification of triterpenoid centelloids in Centella asiatica (L.) Urban by densitometric TLC. J Planar Chromatogr - Mod TLC. 2011;24(1):82-7.

5. Zhang C, Niu J, Chong Y, Huang Y, Chu Y, Xie S, et al. Porous microspheres as promising vehicles for the topical delivery of poorly soluble asiaticoside accelerate wound healing and inhibit scar formation in vitro and in vivo. Eur J Pharm Biopharm. 2016;109:1-13.

6. Setya S, Talegaonkar S, Razdan BK. Nanoemulsions: Formulation methods and stability aspects. World J Pharm Sci. 2014;3(2):2214-28.

7. Sax B, Schön G, Paasch S, Schwuger M. Dielectric spectroscopy-a method of investigating the stability of water-oil emulsions. Colloid Polym Sci. 1988;109-14.

8. Allen L, Popovich $N$, Ansel H. Ansel's pharmaceutical dosage forms and drug delivery systems. Philadelphia: Lippincott Williams and Wilkins. 2013.

9. Pramono S, Ajiastuti D. Standarisasi ekstrak herba pegagan (Centella asiatica (L.) Urban berdasarkan Kadar asiatikosida secara KLt-Densitometri. Majalah Farmasi Indonesia. 2004;15(3):118-23.

10. Suminar M, Jufri M. Physical stability and antioxidant activity assay of a nanoemulsion gel formulation containing tocotrienol. Int J Pharm. 2017;9:140.

11. Reimer $L$, Kohl $H$. Transmission electron microscopy: Physics of image formation. New York: Springer. 2008.

12. Huynh-Ba K. Handbook of stability testing in pharmaceutical development. New York: Springer. 2009.

13. Gupta K, Praveen Kumar. Pharmaceutical nanotechnology novel nanoemulsionhigh energy emulsification preparation, evaluation and application. Pharm Res. 2010;3(1):117-38.

14. Lachman L, Lieberman HA, Kanig JL. The theory and practice of industrial pharmacy. Philadelpia: Lea and Febiger. 1976.

15. Barel AO, Maibach HI, Paye M. Handbook of cosmetic science and technology. New York: Informa Healthcare. 2014

16. Floury J, Bellettre J, Legrand J, Desrumaux A. Analysis of a new type of high pressure homogeniser. A study of the flow pattern. Chem Eng Sci. 2004;59(4):843-53.

17. DeLuca T, Michael Kaszuba, Kevin Mattison. Optimizing Silicone Emulsion Stability Using Zeta Potential. Am Lab. 2006;38(13):14-15.

18. Sinko P. Martin's physical pharmacy and pharmaceutical sciences. Philadelphia: Lippincott Williams and Wilkins. 2006

19. Barry BW. Novel mechanisms and devices to enable successful transdermal drug delivery. Eur J Pharm Sci. 2001;14(2):101-4.

Article History: Submission Date : 31-01-2018 ; Revised Date : 23-02-2018; Acceptance Date : 14-03-2018.

Cite this article: Hanifah M, Jufri M. Formulation and Stability Testing of Nanoemulsion Lotion Containing Centella asiatica Extract. J Young Pharm. 2018;10(4):404-8. 